\title{
ENTRE EL PROTECTORADO Y LA REPÚBLICA DEL SAGRADO CORAZÓN: EL ECUADOR GARCIANO, 1860-1875
}

\author{
Ana Buriano \\ Instituto de Investigaciones Dr. José María Luis Mora
}

INTRODUCCIÓN

Valorar el proyecto político que desarrolló García Moreno en Ecuador, en medio de las interrogantes sobre las formas de gobierno preferidas por los intentos de organización nacional en Latinoamérica, exige reflexionar sobre la relativa lateralidad que el monarquismo ha tenido en la consideración de la "ecuatorianística" para el periodo garciano. ${ }^{1}$ Si bien la tendencia ecuatoriana no está totalmente huérfana de estudios, cierto es que Juan José Flores centralizó

Fecha de recepción: 7 de enero de 2015

Fecha de aceptación: 20 de abril de 2015

1 Entre los estudios dedicados al tema mencionamos: Howe, "García Moreno's Efforts”, pp. 257-262; RoberTson, García Moreno's Dream; Loor, Cartas, vol. 2, pp. 1-16 y vol. 3, pp. 3-15; Olsina, "Relaciones diplomáticas”, pp. 39-54; LARA, La vitrina. 
la atención historiográfica sobre el tema. ${ }^{2}$ Y ello tiene explicación. Una vez que fracasó la oferta de protectorado francés que García buscó en los albores de su administración, la consideración del posible monarquismo garciano fue relegado a la condición de pecado original que la historiografía liberal archivó, ya para caracterizar el poder omnímodo que ejerció, ya para sacarlo a relucir cuando era necesario cuestionar su aporte a la construcción de la nación ecuatoriana. ${ }^{3}$ Tampoco será eje de análisis del presente artículo, cuyo objeto es presentar en sus grandes líneas la propuesta garciana, sino que intentará integrarlo dentro de la explicación histórica dedicada a desentrañar ese singular proyecto de organización nacional.

Entre el "vengador y mártir del derecho cristiano" del padre Berthe y "el santo del patíbulo" de Carrión, ${ }^{4}$ el tema que nos ocupa quedó atrapado en la polarización que ocasionó el personaje y de la que no pudo escapar la historiografía, desde sus primeras expresiones. El conservadurismo y la figura de don Gabriel, reclamada por los estudios históricos afines, fueron conceptuados como traidores por su anexionismo y antiamericanismo. Su magnetismo trascendió fronteras: fue adorado por la reacción nacionalista argentina

${ }^{2}$ Gimeno, Una tentativa monárquica; Van Aken, El rey de la noche. En la Introducción de esta obra Van Aken propone varias hipótesis para fundamentar el poco interés académico que, en general, suscitó el monarquismo en América Latina. Van Aken, El rey de la noche, pp. 17-27.

3 Benítez Vinuenza, Ecuador, p. 197; Carrión, García Moreno, pp. 409-410, 557-558.

4 Berthe, García Moreno; Carrión, García Moreno. Matizado por obras equilibradas y documentadas, como la de Robalino Dávila, Orígenes del Ecuador. 
con Gálvez y satanizado por el estudio "psicopatológico" del cubano Agramonte. ${ }^{5}$

La renovación historiográfica iniciada a fines de los años setenta realizó un serio intento de reconceptualización de la historia republicana de Ecuador y dedicó una consideración privilegiada al periodo garciano, de cuyos logros somos deudores quienes luego no pudimos sustraernos a la seducción de la figura y el periodo. ${ }^{6}$ Otras escuelas estudiaron la pervivencia de Jerusalén en la Babilonia del nuevo régimen ${ }^{7}$ y García sigue alumbrando la producción historiográfica en el presente siglo, ${ }^{8}$ pues resulta historiográficamente perturbador. No embona con el "deber ser" de un conservador. Ultramontano para unos, negado en su identidad conservadora por otros, analizar el proyecto que sustentó entre 1860 y 1875 sigue siendo un desafío historiográfico.

\section{EL PROYECTO DE PROTECTORADO FRANCÉS}

Revalorar el esfuerzo de organización nacional que hizo este régimen, "en épocas de liberalismo rampante", montado en la ola del progreso mientras consagraba la República al Sagrado Corazón de Jesús, exige comprender, como bien establece Maiguashca, que ni las identidades ni los proyectos políticos

5 Gálvez, Vida; Agramonte, Biografía.

6 Entre las principales expresiones de estas corrientes están Ayala Mora, “Gabriel García Moreno y la gestación”, pp. 124-160, y del mismo autor, Lucha y "El periodo garciano", pp. 197-235; MAIGUASHCA, "El proyecto garciano” y “El proceso de integración”, pp. 355-420.

7 Démelas y SAInT-Geours, Jerusalén y Babilonia.

8 Henderson, Gabriel Garcia Moreno and Conservative; Buriano, Navegando y Buriano (comp.), El "espiritu nacional”.

9 Buriano, “Ecuador: un régimen”, pp. 211-256. 
surgen cuajados de antemano sino que se forjan sobre "la marcha [...] en diálogo con las circunstancias”. ${ }^{10}$ Circunstancias que fueron variadas durante los tres lustros en que el garcianismo ejerció el poder. Y por más que el proyecto reflejara una imagen pétrea debió navegar en mares agitados.

García Moreno se instaló en el gobierno en medio de una crisis catastrófica. Los dos proyectos que lo precedieron ${ }^{11}$ no lograron dotar de unidad nacional a un país fragmentado y regionalizado. El fortalecimiento de la producción cauchera, del cacao y la cascarilla permitió la entronización, a partir de mediados de siglo, de una propuesta de perfil liberal, ${ }^{12}$ que acentuó la polarización a partir de un conjunto de reformas afines a esta tendencia. ${ }^{13}$ Las transformaciones que impulsaron esos gobiernos sumieron a Ecuador en una de las mayores crisis de su historia. A partir de las reclamaciones que hizo Perú sobre los territorios amazónicos cedidos en los tratados que celebró Ecuador con la Asociación de acreedores británicos, para solventar las deudas de la independencia, el puerto de Guayaquil fue invadido por la flota peruana en 1859 y

10 Maiguashca, “El proyecto garciano”, p. 257.

11 El centralista de Juan José Flores y el descentralista impulsado por las élites guayaquileñas que lo derrocaron en 1845 .

12 Ayala Mora, Lucha, pp. 95-96.

13 Tales como el establecimiento del sistema por jurados, la expulsión de la Compañía de Jesús, la manumisión de esclavos, la abolición de las protecturías indígenas y, en 1857, a partir de una coyuntura propicia para basar los presupuestos estatales en los ingresos de aduana, la extinción del tributo y su sustitución por una contribución subsidiaria que gravaba a todos los habitantes. José Ma. Urbina, el impulsor de estas transformaciones, se granjeó el odio de la aristocracia terrateniente, que lo consideró un "rojo" radical, enemigo de la Iglesia, que basaba su poder en unas fuerzas armadas, sus batallones "tauras” integrados con negros manumisos y montubios costeros. 
ello detonó un caos disgregador latente. El país se balcanizó en cuatro gobiernos, ${ }^{14}$ mientras Perú y Colombia programaban seccionarlo e integrar los fragmentos dentro de sus fronteras, que ejercían una intensa atracción sobre las regiones.

Es en este marco, y como integrante del triunvirato del gobierno de Quito, que García Moreno gestionó, a fines de 1859, ante Emile Trinité - el encargado de Negocios de Francia en Ecuador - y ante la diplomacia española, poner la República bajo la protección de esas monarquías católicas. Pronto descartó a España y concentró su oferta en Francia. Propuso que se hiciera en condiciones "análogas a las existentes entre Canadá y Gran Bretaña”, es decir, bajo el estatus de dominio y con un gobierno autónomo y estable. Fundamentó esta oferta diciendo que era el sentimiento "de todo hombre de orden", de aquellos "que estamos cansados de luchar contra el desenfreno de la soldadesca y la turbulencia de los demagogos; [...] los que trabajamos en vano por contener la anarquía que nos deshonra y empobrece, y vemos avanzar rápidamente el torrente arrasador de la raza angloamericana”. En el protectorado, decía García, “encontraríamos [...] la civilización en la paz y la libertad en el orden [...] ${ }^{15}$ Para estas gestiones contó con la aprobación de algunos miembros del gobierno provisorio que en el futuro no le serían afines, de modo que el desánimo parecía involucrar a varios sectores de las élites serranas. ${ }^{16}$ Trinité no dio curso

${ }^{14}$ Los de Quito, Guayaquil y Cuenca, mientras la pequeña Loja se segregó y formó un distrito federal independiente.

15 “García Moreno a Trinité, en Loor, Cartas, vol. 2, pp. 155-157.

${ }^{16}$ Este acuerdo que parece haber sellado con sus colegas triunviros, aunque muy cuestionado, está documentado por el anuncio que le hizo a Trinité de que podría discutir los detalles con su colega triunviro Manuel 
a la propuesta. Quizá consideraba incierta la suerte del triunvirato quiteño en guerra con el gobierno de Guayaquil.

Francia fue, sin duda, preferida frente a España. Además de un mal entendimiento con la diplomacia española y del poco hispanismo que caracterizó a la corriente garciana, cierto es que don Gabriel era un francófilo que había regresado poco antes deslumbrado del París de Luis Napoleón, donde vivió exiliado entre 1855 y 1856. Le asiste razón a Rafael Rojas cuando reclama la escasa consideración que los recientes estudios hemos dedicado a esa etapa de la vida del personaje. ${ }^{17}$ Aunque en su correspondencia no existen referencias a los proyectos monarquistas que se gestaban ante las cortes europeas por esos años, no es aventurado deducir que algún tipo de fascinación debieron haber ejercido sobre él las propuestas de "latinidad" que promovía la Francia imperial y que se expresaban también en el pensamiento católico con el que estableció un profundo contacto durante esa estancia parisina..$^{18}$ Las motivaciones concretas de este primer intento

Gómez de la Torre, quien viajaría a Guayaquil y estaría interiorizado del plan. Olsina, "Relaciones diplomáticas", p. 42.

17 Rojas, "Plumas", p. 18.

${ }_{18}$ Poco tiempo después de que en los medios intelectuales se manejara el concepto de "latinidad", la Iglesia católica lo asumió con la fundación del Colegio Latino Americano, por monseñor Víctor Eyzaguirre, que en 1867 modificó su nombre por el de Pío Latino Americano. Ayala Mora, "El origen del nombre", p. 232. Citado en Buriano, "El 'espíritu' ”, en prensa. Como señala Rojas, "[...] los conservadores hispanoamericanos valoraron positivamente la contención del republicanismo y el socialismo más radicales, que ejerció el Segundo Imperio, y sus simpatías por una reconstrucción de la hegemonía latina y católica de las monarquías mediterráneas en la región, que limitara la creciente influencia estadounidense. En la elaboración de su proyecto político, en París, García Moreno tomó en cuenta esas condiciones favorables, como puede constatarse 
parecen obvias: buscaba el apoyo de una potencia poderosa que permitiera salvaguardar la unidad territorial de Ecuador frente a la invasión peruana y que lo rescatara de la anarquía disgregadora. Y, por cierto, no lo hacía solo.

Ya que no recibía respuesta de Francia, don Gabriel selló una alianza con el exiliado general Juan José Flores, de regreso de sus periplos ante las cortes europeas que finalmente se plasmaron en 1846, con el fallido intento de establecer el Reino Unido de los Andes bajo la protección de María Cristina de Borbón. ${ }^{19}$ Planes que, por cierto, horrorizaron entonces a un García Moreno muy republicano que los censuró acremente desde su periódico El Vengador. ${ }^{20} \mathrm{Sin}$ embargo, el apoyo del "padre de la patria" le permitió derrotar al jefe supremo de Guayaquil y pactar la reunificación del país. Así, convocó una convención constituyente que lo designó presidente en 1861.

Con el país unificado y estrenando Constitución, resulta más complejo entender las razones por las que, el 22 de junio de 1861, reiteró la oferta en los mismos términos a Amédée Fabre, el sucesor de Trinité. Desde la presidencia la propuesta alcanzó gran repercusión. Encontró un encargado de negocios receptivo, que le dio rápido trámite y se convirtió en un activo promotor del protectorado. Más allá de la existencia en Ecuador de un sentimiento monárquico difuso

en la sintonía que establecieron sus ideas con la obra del presbítero chileno José Ignacio Víctor Eyzaguirre Portales, fundador del Colegio Pío Latinoamericano de Roma, quien fuera nombrado por Pío IX, pronotario apostólico de la Santa Sede". Rojas, "Plumas", p. 19.

${ }^{19}$ Con la propuesta de coronar a alguno de los hijos de su segundo matrimonio con el Duque de Riánsares, posiblemente Agustín Muñoz y de Borbón, de 13 años.

${ }^{20}$ Van Aken, El rey de la noche, p. 361, n. 66. 
que impresionaba mucho a su homólogo estadounidense, ${ }^{21}$ Fabre comprendía el real alcance del dilema que subyacía en la propuesta y que trascendía una sólida preferencia por la forma de gobierno monárquica. Así exaltaba ante su ministro de Relaciones Exteriores, Eduardo Antonio Thouvenel, la franqueza del presidente. Le decía entonces:

Tiene [García Moreno] la convicción [...] de que la América del Sur vuelve al salvajismo. Se ha pronunciado la palabra monarquía [como institución para salvar al país] -me dice. Remedio inútil: elijamos mandatario a uno de los nuestros o traigamos a un príncipe el pueblo rechazará a cualquiera de los dos. Tenemos el ejemplo de Iturbide y la inestabilidad de los gobiernos hispanoamericanos. No es una institución monárquica o republicana lo que nos hace falta; es una fuerza moral, material que resista los embates de la anarquía. ${ }^{22}$

Apremiado por las presiones diplomáticas de Perú, García Moreno ordenó en septiembre de 1861 a Antonio Flores Jijón, su ministro en París, impulsar un plan más extremo que cedía las Galápagos para que Francia fincara una estación naval en el Pacífico y tierras en el Amazonas. Ofrecía además su gestión para conformar el Reino Unido de los Andes bajo un príncipe designado por el emperador. ${ }^{23}$

${ }^{21}$ El embajador Friedrich Hassaureck entendía que la forma monárquica tenía mayor cantidad de partidarios de los que podría suponerse. HasSAURecK, Cuatro años, p. 272.

22 "Carta de Amédée Fabre, Encargado de Negocios en Ecuador a Eduardo Antonio Thouvenel, Ministro de Negocios Extranjeros de Francia, Quito, 1ero. de febrero de 1862", en Loor, Cartas, vol. 3, p. 6.

${ }^{23}$ Robalino Dávila, Orígenes del Ecuador de hoy, p. 208. "Documento confidencial transmitido por el Encargado de Asuntos del Ecuador. 
A cambio solicitaba la mediación de Francia para calmar los ánimos bélicos de Perú y arreglar las cuestionadas fronteras del sur.

Cierto es que desde agosto las relaciones entre Ecuador y Perú se habían tensado de manera extrema. El Comercio de Lima publicó el 11 de marzo de 1861, al día siguiente de la designación presidencial de García, las cartas dirigidas a Trinité que habían sido robadas por el cónsul Lapierre, secretario de la Legación en Guayaquil. ${ }^{24}$ Más grave aún fue la situación una vez que la Asamblea de 1861 desconoció el tratado de Mapasingue y negó la autoridad de Guillermo Franco, el jefe supremo de Guayaquil, para sellar este acuerdo con el mariscal Ramón Castilla. ${ }^{25} \mathrm{Y}$ aún más; al discutir su régimen interior dispuso de los territorios involucrados en la disputa. La hostilidad entre ambos vecinos se tornó extrema a partir del 24 de agosto, cuando el ministro de Relaciones Exteriores de Perú envió notas diplomáticas a Ecuador exigiendo el cumplimiento del tratado y giró un llamado a los gobiernos sudamericanos, con motivo de la restauración en Santo Domingo, en el que insinuaba la traición de Ecuador a la causa de la independencia y la

Oferta de protectorado, de cesión de las Islas Galápagos. Proyecto de Monarquía de los Andes”, AMAE, MQO, CPC, París, Parte III. Ecuador, ff. 101-102 (5 sep. 1861), citado en Olsina, "Relaciones diplomáticas", pp. 48-49.

${ }^{24}$ Olsina, "Relaciones diplomáticas", p. 43.

${ }_{25}$ Por este tratado se declaraban nulas las adjudicaciones a los británicos y se comprometía una rectificación de límites con Perú por medio de una comisión mixta, a partir de la aceptación provisional de los establecidos por la Real Cédula de 1802. "Decreto que declara nulo y de ningún valor el tratado de Mapasingue”, El Nacional, Quito (20 abr. 1861), p. 2, en LC, Registro oficial, microfilm $35 \mathrm{~mm}, \mathrm{r} .7$. 
república. ${ }^{26}$ De este modo no es extraño que García apelara a las potencias europeas en busca de protección. No sólo lo hizo con Francia sino también con Gran Bretaña, que deploraba cualquier conflicto que afectara sus intereses comerciales. La mediación de ambas parece haber sido efectiva para contener la agresividad de Castilla. ${ }^{27}$

La correspondencia entre Fabre y Thouvenel demuestra que Francia sopesó la propuesta de García. ${ }^{28} \mathrm{El} 1$ o de febrero de 1862 Fabre presentó al ministro un informe de 52 páginas en respuesta a distintas consultas que le había efectuado. Se trata de un documento en particular esclarecedor sobre la forma en que Francia valoraba los ofrecimientos de

26 "Nota del Excelentísimo Señor José Fabio Melgar, Ministro de Relaciones Exteriores de la República del Perú, exigiendo el cumplimiento del proyecto de tratado hecho en Guayaquil el 25 de enero de 1861", El Nacional (9 oct. 1861), pp. 1-2, en LC, Registro oficial, microfilm 35 mm, r. 7; "Nota del Ministro de Relaciones Exteriores del Perú pidiendo explicaciones sobre el proyecto de incorporación del Ecuador a una potencia europea", El Nacional (9 oct. 1861), p. 4, en LC, Registro oficial, microfilm 35 mm, r. 7; "Nota del mismo Ministerio (Perú) remitiendo copia de la circular dirigida a los gobiernos de América protestando de la anexión de la República de Santo Domingo a la monarquía española”, El Nacional (9 oct. 1861), p. 6, en LC, Registro oficial, microfilm 35 mm, r. 7. En el mismo número de El Nacional, se transcriben las duras respuestas del ministro de Relaciones Exteriores de Ecuador, Rafael Carvajal, así como notas editoriales e inserciones.

${ }^{27}$ Decía García Moreno a Fabre: “'podemos contar con vuestra influencia a fin que [el gobierno imperial] impida el bloqueo y obligue al gabinete de Lima a reanudar relaciones?". "García Moreno a Fabre, 7 de septiembre de 1861", en Loor, Cartas, vol. 2, p. 4. Otras referencias a la mediación de Inglaterra solicitada por Flores Jijón y las presiones de Francia sobre Castilla en Loor, Cartas, vol. 2, pp. 6-12.

${ }^{28}$ El análisis de la correspondencia entre Fabre y Thouvenel se apoya en BuRIANO, "Ecuador: un régimen conservador", pp. 211-256. 
las convulsas repúblicas latinoamericanas. En una primera parte del informe el entusiasta Fabre describía la situación de los partidos: el grado de desmoralización y dispersión en que se encontraba el "democrático" y el ánimo optimista y confiado que privaba en el "aristocrático", cuyo jefe indiscutible era García Moreno. Sin embargo, no se animaba a pronosticar el resultado del voto legislativo en una consulta en torno del protectorado más allá de las seguridades de éxito que le ofrecía el presidente.

Como buen agente experimentado desplegaba los pros y contras de la anexión. A riesgo de ser contrafáctica, no puedo omitir señalar que si la oferta hubiera sido aceptada, las relaciones entre protector y protegido no habrían sido idílicas, pues Fabre alertaba a su gobierno de algunos problemas que nublaban una administración caracterizada como sólida. Le preocupaba la violencia represiva que generaba reclamaciones del cuerpo diplomático, inglés y brasilero, ${ }^{29}$ y el fanatismo religioso del régimen, que confiaba pudiera disiparse en el transcurso por las luces del siglo:

No hay necesidad de proclamar en este país el principio de libertad religiosa en la forma en que se practica en Francia según costumbre tradicional. Por ahora podría dejarse a los ecuatorianos, sin inconveniente alguno, la satisfacción de que continúe el catolicismo como único culto público; más tarde, con el transcurso de los años, el trato habitual con anglosajones, franceses o extranjeros protestantes, el progreso de las luces e ideas de tolerancia permitirán, sin duda alguna, un

29 "Informe de Fabre a Thouvenel, Quito, 1ero. de febrero de 1862", en Loor, Cartas, vol. 3, p. 6. 
cambio en la legislación ecuatoriana y un régimen religioso menos absoluto. ${ }^{30}$

Juzgaba también que la fama humanista francesa de respeto a los derechos del hombre haría que la anexión fuera considerada una opción aceptable hasta para los opositores. ${ }^{31}$ Este mismo humanismo sería adecuado también para promocionar “instituciones parlamentarias tan libres como aquellas que goza Canadá, y siempre que el parlamento ecuatoriano no atente contra nuestros establecimientos militares le dejaremos en completa libertad de gobierno". ${ }^{32}$ Ante estos considerandos es imposible no evocar la decepción que sufrieron los conservadores mexicanos con el Segundo Imperio y suponer que si Francia hubiera aceptado el protectorado habría ocurrido aquello que Erika Pani definió bajo el aserto de "El tiro por la culata". ${ }^{33}$

Desde el punto de vista comercial - proyectaba el diplomático - Francia abriría sus puertos al cacao y a otros productos de la agroexportación, lo que garantizaría el "concurso entusiasta del comercio" hacia la anexión. ${ }^{34} \mathrm{El}$ ejército era un tema delicado y muy conversado con García Moreno y con Flores, por supuesto. Fabre consideraba que la oficialidad nacional no aceptaría su desplazamiento. Habría que mantenerlos en sus grados y halagarlos, ascendiéndolos dentro del ejército francés, hecho que sería muy "lisonjero" para los escogidos aunque: "forzosamente [por

\footnotetext{
30 "Informe de Fabre a Thouvenel", en Loor, Cartas, vol. 3, p. 7.

31 "Informe de Fabre a Thouvenel", en Loor, Cartas, vol. 3, p. 8.

32 "Informe de Fabre a Thouvenel", en Loor, Cartas, vol. 3, p. 8.

33 PANI, "El tiro", pp. 99-122.

34 "Informe de Fabre a Thouvenel”, en Loor, Cartas, vol. 3, p. 7.
} 
falta de instrucción y capacidad en su desempeño] los franceses tendrían que reemplazarlos". ${ }^{35}$

Había otros problemas, claro está: los vecinos eran peligrosos, la resistencia podía extenderse a la región andina y la presencia francesa en el Pacífico podía complicar las cosas cuando Estados Unidos se desocupara de sus problemas internos. ${ }^{36}$ Fabre calculaba las fuerzas militares francesas que sería necesario involucrar en distintos escenarios. $\mathrm{Si}$ el plebiscito no les fuera favorable, y si el ejército ecuatoriano se opusiera y recibiera el apoyo de Perú y Nueva Granada, habría que invertir "algunos millares de hombres". Sin embargo, lo previsible era, a su entender, que el protectorado fuera aceptado en la elección y, por lo tanto, sólo habría que enfrentarse con las potencias vecinas que podrían ser vencidas por "un pequeño cuerpo francés, de algunos centenares de hombres, sirviendo de núcleo, de enlace, al ejército ecuatoriano reforzado en el comando por algunos oficiales o sub-oficiales franceses". ${ }^{37}$

Diferente sería la situación si Francia tuviera que vérselas con Inglaterra o Estados Unidos. El agente diplomático inglés, Mr. Fagan, le daba buena impresión ya que era un irlandés católico comprensivo de la impotencia interna para controlar la anarquía y, por lo tanto, proclive a no oponerse a que Francia gobernara Ecuador. No obstante, advertía Fabre: "Otra cosa sería la fundación de un imperio colonial y marítimo, sobre todo, si como lo creo, las repúblicas de Venezuela y Nueva Granada, no tardasen en pedir

\footnotetext{
35 “Informe de Fabre a Thouvenel”, en Loor, Cartas, vol. 3, p. 7.

36 “Informe de Fabre a Thouvenel”, en Loor, Cartas, vol. 3, pp. 8-12.

37 “Informe de Fabre a Thouvenel”, en Loor, Cartas, vol. 3, p. 12.
} 
su anexión a Francia en forma semejante a la del Ecuador”, caso en el que habría que dar garantías de neutralidad para el paso de Panamá. ${ }^{38}$ Consideraba, también con cuidado, el problema de las tres deudas que sostenía Ecuador: la Mackintosh, la de la nueva compañía en Londres, y la llamada de los acreedores ingleses. Detallaba las cinco concesiones territoriales que se habían hecho y valoraba con optimismo que si Francia reconocía a los acreedores, éstos quedarían inmensamente satisfechos ya que no contaban con verdadero apoyo de Inglaterra a sus deudas perpetuas. ${ }^{39}$ Desestimaba el peligro que pudiera suponer España, tanto porque su representante era un hombre desacreditado por su conducta moral y pública, como porque la antigua metrópoli gozaba de la animadversión general de sus excolonias. "La palabra reconquista está en todos los labios, bajo todas las plumas y en todos los corazones como una maldición para España."40

Fabre trataba de contagiar al Ministerio con su entusiasmo y apelaba para ello a una visión geopolítica continental que juzgaba grata a los planes expansionistas imperiales: "conviene hacer de este país la base del imperio colonial y el asiento de una potencia marítima imponente, que sea nervio de Francia y defienda puntos estratégicos militares, como las islas Galápagos y Guayaquil”. ${ }^{41}$ Todas estas valoraciones fueron inútiles porque Thouvenel no compartía el entusiasmo de su hombre en Ecuador ${ }^{42}$ y el 29 de febrero

\footnotetext{
38 “Informe de Fabre a Thouvenel”, en Loor, Cartas, vol. 3, p. 10.

39 “Informe de Fabre a Thouvenel”, en Loor, Cartas, vol. 3, pp. 10-12.

40 "Informe de Fabre a Thouvenel”, en Loor, Cartas, vol. 3, pp. 9-10.

41 "Informe de Fabre a Thouvenel”, en Loor, Cartas, vol. 3, p. 8.

42 Robalino Dávila, Orígenes del Ecuador de hoy, pp. 211-212.
} 
de 1862 puso fin a las gestiones. Con gran realismo político y menosprecio le señaló a Fabre: "las adquisiciones territoriales en aquellos países distantes [...] nada añadirán a nuestro poderío $[\ldots]$ y pueden $[\ldots]$ envolvernos en querellas intestinas". Con gusto Francia prestaría una influencia que, dijo: "contribuiría poderosamente al progreso moral y el mejoramiento [...] que estos vastos países necesitan todavía para alcanzar el nivel general de la civilización moderna”. Le explicó que ese era el esfuerzo que intentaba Francia en México, cuyo buen resultado le haría esperar "que la porción sana de la población de Sudamérica contemple un ejemplo que sería saludable seguir". ${ }^{43}$ Así, el ejemplo de México debía ser suficiente para un país como Ecuador, geográficamente desarticulado, convulso e incomunicado en el interior, que exigiría fuertes inversiones y miles de hombres. Ecuador no era México y Francia se estaba involucrando en esa aventura. ${ }^{44}$

\section{LAS BASES DEL POSIBLE “MONARQUISMO” DE DON GABRIEL}

Corresponde preguntarse, ¿qué impulsó a don Gabriel a insistir en esta segunda oferta? ¿Era acaso un monárquico contumaz? Aunque en las propuestas de protectorado aparece la mano innegable de Juan José Flores, quien

43 AMAE, MQO, CPC, París, Parte III, Ecuador 5, f. 272 (28 de febrero de 1862), citado en Olsina, "Relaciones diplomáticas", p. 52.

${ }^{44}$ Fabre le comentó a su ministro que el presidente estaba desilusionado y su gabinete lo consolaba diciéndole "Cuando la cuestión de México se haya arreglado, tal vez Francia se acuerde de nosotros”. Robalino DáviLA, Orígenes del Ecuador de hoy, pp. 216-217. 
había acuñado de tiempo atrás una fundamentación antirrepublicana, ${ }^{45}$ entiendo que García fue sincero cuando le comentó a Fabre que la suerte de Ecuador no pasaba por la monarquía o la república sino por una fuerza que permitiera resistir la anarquía. Y en junio de 1861, la recién finalizada Asamblea Constituyente lo había convencido de que el país carecía de esas reservas. La Constitución aprobada era, en su consideración, la mejor prueba de esa incapacidad pues ataba las manos al Ejecutivo para ejercer un poder centralizado y omnímodo como el que creía necesario. ${ }^{46}$ No era la herramienta adecuada para crear una fuerza moral y material que liberara a Ecuador del "salvajismo" y la "anarquía”. En cambio el protectorado le permitiría anular esa Constitución y aprobar un marco legal más ajustado a su sentir. ${ }^{47} \mathrm{Al}$ finalizar la Constituyente de 1861 García estaba hondamente decepcionado de sus resultados. Decía a Fabre:

$45 \mathrm{El}$ antirrepublicanismo de Flores puede rastrearse desde sus épocas de subordinado a Bolívar. La propuesta del Reino Unido de los Andes guarda indisimulables similitudes con los diversos planes que pergeñó Flores en la década de 1840 en estrecha conexión con el general Andrés de Santa Cruz. Van Aken, El rey de la noche, pp. 47, 267-300.

${ }^{46}$ García sostenía que esa Constitución era insuficiente para "impedir el mal ni hacer el bien". "García a Salazar, Guachalá, 14 de junio de 1868", en Loor, Cartas, vol. 4, pp. 19-20. Para ampliar la información sobre la Constitución de 1861 véase Maiguashca, "The Electoral Reforms”, pp. 87-116; Henderson, “La Constitución”, pp. 47-69.

${ }_{47}$ Así lo proponía de manera explícita, según informaba Fabre a su ministro: "Si su gobierno está dispuesto a aceptar la proposición que le hago convocaré enseguida a mis colegas [...] para reunir una convención que conozca y vote el pacto de unión del Ecuador con Francia. [...] ahora el asunto tardará un poco más, porque tenemos una Constitución y tenemos que comenzar por reformarla [...]". "Informe de Fabre a Thouvenel, Quito, 27 de junio de 1861”, en Loor, Cartas, vol. 2, p. 2. 
"Yo soy presidente hoy día, y parece que los presidentes gobernamos; pero no os equivoquéis: esto sólo es una tregua, nuestro estado normal es la revolución". ${ }^{48}$ Creemos que la Constitución de 1861 y los debates que la rodearon, aún más que la amenaza peruana, actuaron como detonantes del renovado esfuerzo por obtener la protección de Francia. ${ }^{49}$

Cierto es que la correlación de fuerzas en la Constituyente de 1861 no favoreció a la tendencia garciana aún incipiente y carente de unidad doctrinaria. Pese a ello, en esa instancia legislativa predominó cierto clima de concertación ante el temor a la desagregación y la amenaza externa. García fue visto por las élites como un gobernante que podía dar estabilidad y que se proyectaba al ámbito nacional por encima de la "provinciocracia". Los cambios que impulsó, es decir, la representación proporcional a la población y la ampliación del cuerpo ciudadano generaron en torno de su tendencia un espacio de expectativa que permitió al garcianismo acercarse adhesiones de diverso signo. Sin embargo, muy prevenida contra los desbordes del Ejecutivo, la Constituyente le impuso varios frenos que impactaron la administración del Estado, como la prohibición de la pena de muerte por delitos

48 "Informe de Fabre a Thouvenel, Quito, 27 de junio de 1861", en Loor, Cartas, vol. 2, p. 2.

${ }^{49}$ Esta opinión podría ser cuestionada si se la confronta con el más o menos velado apoyo que dio al Imperio de Maximiliano y el acendrado antiamericanismo que demostró al declarar la neutralidad durante la Guerra del Pacífico. Quizá no todo fue antiamericanismo, sino que no quiso enfrentar los daños económicos que sufrió Ecuador durante el interregno cuando, en 1867, se plegó a la Unión Americana. El alineamiento contra España, el principal comprador del cacao ecuatoriano, llevó los precios a su mínima expresión y lo convirtió en el país más afectado de los involucrados en el conflicto. 
políticos, la descentralización municipal en el ámbito provincial, la elección directa para todos los cargos de gobierno - aun los locales - y, dos años después, la sustracción de la enseñanza al control del Ejecutivo. De manera que la de 1861 fue la más descentralista de las constituciones que rigieron en el país y con ella no era posible, entendían los garcianos, darle viabilidad a Ecuador.

Aunque en el seno de la Asamblea no se desarrolló una discusión doctrinaria del nivel de la reseñada por Elías Palti en México, donde una estructura de bandos políticos más arraigada y consistente permitió a los "monarquistas", entrecomillados, una elaboración ideológico conceptual mayor en torno de la irracionalidad que guardaba la doble concepción liberal de ciudadanía, ${ }^{50}$ fue precisamente en este plano donde se produjeron los más encarnizados debates. En un marco más pragmático y menos teórico, los garcianos propusieron tanto la limitación de las ocasiones para el ejercicio del sufragio, como la calificación de la ciudadanía. Sus opositores se convirtieron así en los cultores de las "libertades inmoderadas", los demagogos partidarios de multiplicar las instancias electorales, cuando era evidente que "elecciones" y "revoluciones" constituían una dupla indisoluble. Los garcianos querían ciudadanía ampliada, pero no reconocían el "voto derecho", sino el "voto función", como lo establece Rosanvallon. ${ }^{51}$ El voto que posibilita la inclusión del conjunto social en una particular propuesta nacional tenía, de todos modos, una proyección universalista que perfilaba

50 Se refiere a la polémica entablada en la prensa mexicana en torno de la condición del ciudadano, sujeto sometido a la ley y portador a un tiempo de la soberanía. Palti, La invención, pp. 220-233.

${ }^{51}$ Rosanvallon, La consagración, p. 274. 
mejor a su corriente frente a la argumentación opositora instalada en la teoría del ciudadano capacitado. García Moreno quería fincar institucionalmente el control del poder central sobre el conjunto del Estado y "la insuficiencia de las leyes" aprobadas fue una queja continua del inspirador de la propuesta.

A pesar de que la forma de gobierno republicana no fue cuestionada en los debates, ${ }^{52}$ una voz se alzó para exaltar la dictadura de Luis Napoleón. Fue la del diputado Sanz, por Pichincha, quien molesto con la elección popular de gobernadores elogió al régimen autoritario establecido por el príncipe presidente que, dijo, había servido: "para hacer la felicidad de Francia, mientras que entre nosotros las instituciones liberales no nos han servido de escudo contra la arbitrariedad de esos ídolos que ahora se escarnecen y cuya memoria nos horroriza". ${ }^{53}$ Se expuso así a que le recordaran que en Ecuador regía la forma de gobierno republicana y democrática, ante lo que el increpado respondió que él “era tan liberal como otros”, y que si se había referido a Francia era por querer exaltar que "la moralidad y el progreso no son inherentes a la elección popular de los gobernantes". ${ }^{54}$

También cuando se examinaron los artículos 1ero. y 2 do., relativos a la República, algunos diputados insistieron en que se especificara que el ejercicio del poder supremo no podría ser patrimonio de una familia, persona o clase, como ocurría

52 Aunque fueron extensos y encarnizados en torno de las características de esta república.

53 "Intervención del diputado Vicente Sanz, Sesión del 6 de marzo de 1861", en Diario, p. 470.

54 "Respuesta del diputado Nájera, Sesión del 6 de marzo de 1861", en Diario, p. 470. 
en las monarquías pues, a decir del diputado Cuesta: “pudiera suceder también entre nosotros que viniese un estrajero [sic], y ofreciendo conservar la libertad y la independencia, quisiera de este modo hacerse dueño de la República". ${ }^{55}$

Quizá la mayor proximidad con el debate mexicano se suscitó cuando se discutió el sujeto portador de la soberanía, es decir, si ella debía recaer en el "pueblo" o en la "nación”. Fue el diputado Muñoz, en defensa de que se privilegiara la voz "nación”, quien puso sobre la mesa la contradicción que suponía decir que la soberanía reside en el pueblo, pues "si este es soberano se seguiría que el mismo pueblo es el que manda y el que obedece". ${ }^{56}$ Aunque alguna otra referencia existió para identificar los poderes del Estado con las formas de gobierno, en el sentido de que al Ejecutivo le correspondía la monárquica, ${ }^{57}$ lo cierto es que en el caso ecuatoriano y en el marco de la Asamblea, no existió una argumentación antirrepublicana sólida. En todo caso la anarquía no era inherente a la república, según lo demostraba el ejemplo chileno y su Constitución portaliana, sino a las formas federales descentralistas, como las de Nueva Granada.

No podemos dejar de anotar que, en tanto se gestionaba el protectorado y autorizado por la Asamblea de 1861, García Moreno logró firmar un singular y favorable concordato con la Santa Sede en mayo de 1862. El presidente era un hombre extraordinariamente actualizado sobre la realidad

55 “Intervención del diputado Vicente Cuesta, Sesión del 8 de febrero de 1861", en Diario, p. 155.

56 "Intervención del diputado Antonio Muñoz, Sesión del 7 de febrero de 1861", en Diario, pp. 153-155.

57 "Intervención de Vicente Espinosa, Sesión del 6 de marzo de 1861", en Diario, p. 471. 
europea y no podía ignorar el vuelco de Francia en favor de Piamonte, como tampoco desconocía que Pío IX, en función de sus intereses pastorales, estaba dispuesto a defender el principio de intervención, como señala Olimón Nolasco. Sin llegar a afirmar que el concordato se propuso para reafirmar la oferta del protectorado, creo que no pueden perderse de vista los beneficios que García percibió, ya entonces, en sumar el "factor Vaticano", la voluntad papal en pro de su oferta. $^{58}$

Así, una vez que se produjo el rechazo de Francia, el papado fue la "fuerza moral" que el régimen requería y de la que se benefició, aun a riesgo de incrementar la conflictividad, para asentar su proyecto en una Iglesia católica reformada a sangre y fuego. En esta "fuerza moral” basó García su dominación. Con ella se movió con duplicidad y equilibrio entre los jesuitas, las congregaciones laicales modernizantes que promovían el catolicismo social, el clero regular resurgido con el liberalismo católico y reformado bajo una óptica arcaica; interactuó también con las jerarquías vaticanas ilustradas y con un papado enfrentado al liberalismo, del que García Moreno fue hijo dilecto en el continente.

\footnotetext{
${ }^{58}$ Manuel Olimón Nolasco, "El Papa Pío IX y Napoleón III: nerviosismo político en Europa y México", texto presentado en el ciclo de conferencias "Hacia nuestros centenarios. Francia-México" organizado por el Centro de Estudios de Historia de México Condumex, ciudad de México, 25 de abril de 2007 [en línea] http://www.olimon.org/manuel/ponencias/ nerviosismo.htm [consultado el 2 de febrero de 2014]. Citado en BuRIAno, "El espíritu", en prensa.
} 
ECUADOR EN MANOS DE UN JARDINERO SOCIAL

Cierto es que el rechazo del Imperio generó una crisis de conciencia entre las élites gobernantes. Las obligó a aceptar que se trataba de una resolución interna que exigía una verdadera refundación. Había que remover Ecuador desde sus cimientos. Estas élites mentalmente eran proclives a aceptar un proyecto que interviniera a fondo el cuerpo de la nación para modernizarla. Se produjo así un "parteaguas intelectual" 59 que no sería forzado comparar con el remezón que sufrieron las élites mexicanas ante la amputación territorial de 1848. Sin embargo, en sus circunstancias los garcianos no podían permitirse ser tan titubeantes como lo fueron los conservadores mexicanos que, si bien se dedicaron a desmontar argumentativamente el edificio liberal, no lograron erigir uno nuevo en medio de sus propias disensiones, según señala Connaughton. ${ }^{60}$ En un panorama más peligroso en lo internacional y lo regional, ${ }^{61}$ debieron ser menos especulativos, más pragmáticos y decididos.

Entre ellos se alzó la caudillesca figura de un constructor de nación que prometía sacar al país del atraso, modernizarlo, acompasarlo al “espíritu del siglo”, integrarlo no sólo por medio de una infraestructura de comunicaciones, sino también por la extensión de la ciudadanía y de la educación

59 Buriano, Navegando, p. 277. Ambos acontecimientos golpearon la conciencia de las élites, exigieron de ellas un salto intelectual ante el temor a la desagregación y modificaron los parámetros de la vida política en ambos países.

60 Connaughton, “La larga cuesta”, pp. 169-186.

61 El liberalismo se extendía con fuerza arrasadora y los vecinos del área andina se aprestaban a repartirse los territorios del país mal integrado. 
a "las ínfimas clases de la sociedad". La promesa de García se basaba en un manejo eficiente de los recursos fiscales, en sofrenar la anarquía, controlar las corporaciones y establecer el progreso con orden. Su oferta política levantaba sospechas, en especial cuando sellaba relaciones demasiado estrechas con el papado y reprimía de manera salvaje. Le otorgaron, sin embargo, el beneficio de la duda. Era, por lo menos, el único núcleo firme para asirse que las élites encontraron a su alcance entonces. Por ello, lo toleraron y acompañaron durante un tiempo y le permitieron presentarse bajo un espectro más amplio que el de sus propias fuerzas. De alguna manera fueron cooptadas por algunas ofertas políticas, así como por el lenguaje discursivo del proyecto que exaltaba el orden y el progreso, categorías que, por cierto, eran compartidas por las distintas tendencias, gozaban de consenso y se convertían así en elementos que estructuraban el debate. ${ }^{62}$ Una "era de dicha y progreso", afirmaba el discurso garciano en 1862, se abría para el Ecuador bajo la férrea mano de un jardinero que cultivaba el "jardín social”63

\footnotetext{
${ }^{62}$ Palti, La invención, p. 474.

${ }^{63}$ Un poema de la época se refiere de manera explícita a García Moreno como el padre de la patria que con ciencia y brío administra en paz el país y cultiva un jardín social con sus propias manos: "A la digna corona del patriota,/Al cívico laurel del magistrado/Une la flor humilde que aquí brota/El jardín que tus manos ha plantado". "Colegio de Santa María del Socorro", El Nacional (21 nov. 1862), en LC, Registro oficial, microfilm $35 \mathrm{~mm}, \mathrm{r}$. 7. Esta imagen del jardinero, explícitamente mencionada respecto a García Moreno, remite a la metáfora que Zigmunt Bauman (guardabosques convertidos en jardineros) retoma de Gellner (culturas silvestres y culturas cultivadas). Se refiere a aquellas culturas que se reproducen libremente en sociedades apenas custodiadas por guardabosques, por oposición a las cultivadas que ocupan jardineros especializados en mantener la disciplina social. PALti, La invención, pp. 316-325. Es una
} 
de un país dejado hasta entonces al abandono de las fuerzas de la propia naturaleza, ahora que un proyecto prometía disciplinar a la sociedad con ciencia aunada a la religión, en fuerte coincidencia con el modelo político "pastoralista" de Foucault. ${ }^{64}$

\section{EL PROYECTO EN PELIGRO}

Su oferta política tuvo un tiempo moderado de aceptación y participación de las élites regionales en los cargos de gobierno. Pero al fin de su primer mandato la base social de apoyo inicial se estrechó y las élites regionales se alejaron de un proyecto errático en política exterior, extraordinariamente represivo y centralizador en extremo. Más aún. Los cimientos del edificio que construyó con grandes esfuerzos durante su primera administración peligraron seriamente durante el interregno entre sus dos gobiernos (1865-1868), cuando los dos candidatos que impuso no contuvieron una oposición cada vez más estructurada en alianzas interregionales, ${ }^{65}$ que lo obligó a enfrentar unas elecciones competidas, en 1868.

Ecuador vivía tiempos de relativa paz. Amplios sectores consideraban que ya no era necesario depender de un "salvador" cuyos excesos habían tolerado durante un lustro. No todos compartían la inspiración misional de un Estado

metáfora en particular útil para el régimen garciano y no deja de ser sorprendente que en el poema el gobernante sea descrito como el encargado de hacer florecer un jardín.

${ }^{64}$ Foucault, Seguridad, pp. 158, 174-175, 177, 185-187, 206.

${ }^{65}$ Nos referimos a la candidatura del poderoso y brillante Francisco Xavier Aguirre Abad, elevada por una conjunción de cuencanos y guayaquileños con motivo de las elecciones que debieron realizarse en 1869. 
centralizado y fundido con la religión. Muchos creían que García Moreno tenía una religiosidad demasiado política que escondía un deseo evidente de subordinar la Iglesia a un proyecto gubernativo. Otros deseaban impulsar la modernización católica pero en un ambiente de "reconciliación". ${ }^{66}$ No creían benéfico partidizar al país. Les asustaba el rumbo que tomaba su vecina Colombia y se extendía un sentimiento proclive a retrotraer la política a una etapa más consensual. Un nuevo Ecuador católico, moderno, tolerante, fincado en bases civilistas y menos represivas parecía emerger y barrer el proyecto centralista y autoritario. ${ }^{67}$

Pese al rechazo a los partidos las campañas electorales de 1865 y 1868 activaron el campo de la política y las tendencias comenzaron a cobrar identidad. Lo que en 1865 fue "el partido del orden y la religión" adquirió mayor perfil en 1868 cuando, en torno a la candidatura de García, se conformaron las sociedades conservadoras. Él mismo afirmaba que deseaba "sostener con más vigor los principios conservadores". ${ }^{68}$ Cierto es que la oposición cuencana, acusada de liberal católica, reclamaba para sí la condición de "verdaderos conservadores". ${ }^{69}$ No deja de ser sugerente que, mientras en 1861 todos se consideraban "tan liberales como

${ }^{66}$ Henderson, Gabriel Garcia Moreno, p. 141.

${ }^{67}$ Esta particular coyuntura tiene un tratamiento más amplio en BURIANo, "Ecuador 1868", pp. 77-109.

68 "García a Salazar, Guachalá, 14 de junio de 1868”, en Loor, Cartas, vol. 4, pp. 19-20.

${ }^{69}$ Cárdenas los describe como conservadores moderados, conservadores liberales o conservadores progresistas, los "verdaderos conservadores" - como se llamaban a sí mismos-, influidos por el catolicismo social. Surgía así una tendencia que tuvo muchas denominaciones en su decurso pero que terminó nombrándose "progresismo". "El verdadero principio 
el que más", en 1868 la identidad conservadora era disputada por unos y por otros. Las élites ecuatorianas se aferraban a no legitimar la existencia de "partidos", ${ }^{70}$ pero los grupos de opinión se asumían bajo identidades políticas porque la coyuntura electoral de 1868 había potenciado las discrepancias. La posibilidad de un acuerdo entre las fracciones se erosionaba. La prensa, las hojas volantes y hasta las manifestaciones callejeras eran expresión y detonante a un tiempo de esa descomposición. Todos estos medios pugnaban por ganar la opinión pública para su proyecto. El consenso había desaparecido minado por la política en la coyuntura electoral y el debate era un campo de lucha "estratégico"71 que García no había logrado conjurar con su proyecto disciplinario y autoritario.

\section{EL CLÍMAX DEL PROYECTO}

Con un golpe de fuerza, en enero de 1869, el garcianismo se reimplantó en el poder con escasa legitimidad y apoyos

conservador”, El Constitucional, Cuenca (1ํ dic. 1868), citado en CÁRDENAS, Región y Estado, p. 105.

70 Pese a que el espectro político no era incipiente, las élites ecuatorianas y muchas latinoamericanas insistían en no legitimar la existencia de partidos. Asociaban la partidización con el caos, la anarquía y la "demagogia”. Guerra y Palti han estudiado este fenómeno. El primero lo asoció al organicismo del Antiguo Régimen. Palti, por el contrario, lo alejó de su conexión con un pasado retardatario y lo adscribió a un momento moderno de la opinión pública, ligado con la racionalidad del liberalismo clásico que exigía la discusión de un problema concreto al margen del origen político de quien proponía la solución y, por tanto, admitía la existencia de "partidos sabáticos" que actuaban en el momento electoral y luego se retraían. Véase PALTi, El tiempo, p. 175, n. 27.

71 Palti, El tiempo, pp. 192-198. 
menguados, aunque consolidado en torno de sus propias fuerzas. Los garcianos sabían que perdían el consenso que los había llevado al poder en 1861. Pese a ello, entendían que no podían avanzar con todo ese espectro disímil en la obtención de los objetivos máximos que plasmarían en la Constitución de 1869. Recién entonces pudieron desarrollar su proyecto a plenitud.

Un "partido" garciano, centralista y católico impulsó, desde el poder omnímodo, sus objetivos en la segunda Constitución de 1869. Lo hizo mediante una alianza con una Iglesia católica reformada, que terminó por ser casi el único reducto del Estado. García logró así la ciudadanización del conjunto social bajo la exigencia de catolicidad para el ejercicio de la soberanía e impuso la plena centralización del Estado en el Ejecutivo. Contó también con el apoyo de un sistema bancario dispuesto a otorgar los recursos que el gobierno le exigía para desarrollar una propuesta centralizadora que implicaba grandes inversiones sobre todo en lo que a infraestructura de comunicaciones se refiere. Claro está que la capacidad de mediación política que le otorgó la banca emisora implicó que ella ganara espacios en los controles del Estado.

A partir de estas bases, los garcianos emprendieron la construcción de un proyecto de país moderno y progresista, con progreso científico técnico, dentro de un catolicismo basado en el comunalismo cristiano, aunque fuertemente estatista y regalista. Legaron un edificio estatal imperfecto pero más cohesionado de lo que estaba. El municipio cantonal, la sociedad impregnada con la noción de pertenencia a una república "única”, “fundada y refundada por la fe”, asentada en la imagen de un cuerpo ciudadano católico, 
diferente del individualismo ciudadanizante liberal, y la República consagrada al Sagrado Corazón de Jesús, fueron los signos del mito en un Ecuador que trató de presentarse como una nación excepcional y única, fundada y refundada por la fe. "Excepcionalidad" que tuvo capacidad de atracción a partir de la potencialidad inclusiva del voto ampliado y el acercamiento que proporcionaba una devoción que humanizaba a Cristo, que lo situaba en la dimensión del hombre y que atraía el favor de Dios para la nación, que se mantenía pura y devota en épocas del más abyecto ateísmo. ${ }^{72}$

Sin embargo, cuando desarrollaba su mayor obra gubernativa, el proyecto garciano enfrentó un encadenamiento crítico que agudizó las tensiones en un país que vivía transformaciones. Intensos movimientos migratorios modificaban la fisonomía de Ecuador; manufacturas tradicionales se desarticulaban, afectadas por la política de apertura aduanal o atraídas por el ciclo del cacao; el cambio de los circuitos comerciales sacudía la economía portuaria y provocaba quiebres bancarios y de antiguas comercializadoras, al tiempo que incursionaban nuevos capitales agresivos que exigían acelerar el ritmo de los cambios. Los fracasos comenzaron a sumarse a medida que avanzaba la década de 1870. La inconformidad en las regiones era cada vez más intensa y las resistencias a la centralización extrema impedían avanzar en la extensión de la infraestructura de comunicaciones; trababan el acceso a la mano de obra para impulsar los proyectos esenciales. El régimen fue abandonando caminos carreteros y provincias mientras los efectos de la gran depresión y

72 Buriano, Navegando, pp. 335-336. 
las demandas de recursos lo enfrentaron a una fuerte crisis financiera y exportadora, en 1874.

\section{UNA MIRADA FINAL A LA CAÍDA DEL PROYECTO}

El garcianismo no logró nunca una dominación tranquila. Contra la imagen monolítica y aplastante de un poder consolidado que refleja la historiografía tradicional, se erige un Estado compromisario, que debió elaborar mecanismos diversos para sostenerse en el poder, y que debía enfrentar entonces su tercera reelección en circunstancias críticas.

Desde su implantación el régimen estaba acostumbrado al combate y decidido a jugar todas las cartas para darle continuidad a su proyecto. Cuando, en la procesión de abril de 1874, García Moreno arrastraba por las calles de Quito una inmensa cruz, no sólo hacía una verdadera performance de la nación que había buscado construir, sino que intentaba conjurar el hecho incontrastable de que el proyecto decepcionaba a muchos. La intensa dinámica social que había impreso al país amenazaba a un régimen que estrechaba, aún más, sus bases de apoyo. ${ }^{73}$

Con la misma ductilidad con la que el proyecto garciano se manejó en el plano político, fue esbozando también la construcción discursiva de la nación. Ahora más que nunca debía agudizar su ingenio y maximizar ese recurso para mostrar que el "pueblo de la fe" y "la patria de la verdad" eran aún competitivos y tenían un futuro que ofrecer en una época adversa. El discurso periodístico garciano, en su formulación final y plena, que excede las posibilidades de este

73 Véase Buriano, “El 'espíritu’”, en prensa. 
artículo, ${ }^{74}$ despliega la máxima expresión de un proyecto basado en la necesidad de crear el "espíritu nacional”, una nación católica inclusiva, alejada del binomio civilizaciónbarbarie que acunaban algunas élites latinoamericanas. El Ecuador garciano perseguía incluir en su propuesta "a toda la multitud que se contiene en la idea colectiva de pueblo", decían sus ideólogos. Nunca hasta entonces había existido una claridad tan prístina en torno de la distancia que separaba al Estado de la nación.

Esa fue la oferta de la madurez: hacer de Ecuador una nación excepcional y testimonial, enfrentada al mundo de la impiedad, singularidad básica para anclar el sentido de pertenencia en una identidad por oposición. En una época en que el paganismo lo ha invadido todo, cuando Europa, conmovida por la agitación social, los movimientos nacionalistas y unificadores, perdía su función de guía espiritual, surgió en el discurso un nacionalismo ecuatoriano que afirmó las posibilidades del país y su juventud y elaboró una formulación propia, mucho más autónoma. ${ }^{75}$

Claro que el proyecto debía ganar tiempo. Si deseaba reelegirse debía atender las demandas de una opinión pública que lo presionaba en muchos frentes. De modo que se preparó para un nuevo giro, al punto de ofrecer, en el plano discursivo, a su estado como árbitro de opiniones e intereses particulares diversos. Y, aunque logró la reelección su oferta

${ }^{74}$ Para este discurso y su análisis véase BuRIano (comp.), El "espíritu nacional".

${ }^{75}$ Eloy Proaño y Vega, “¿Qué somos, qué podemos?”, El Nacional, Quito (18, 25 nov.; 4, 11, 23 dic. 1874 y 1, 9, 16, 23 y 30 ene.; 6, 13 feb.; 6, 13, 31 mar. y 10 abr. 1875), en LC, Registro oficial, microfilm 35 mm, rs. 11 y 12. 
política fue incapaz de concitar la expectativa esperada. Una conjura de fuerzas diversas puso fin al régimen con el magnicidio del 6 de agosto de 1875.

Entre la inicial oferta de protectorado y la final apelación nacionalista, el garcianismo lo intentó todo. Fue un proyecto activo que si bien se manejó dentro de un conglomerado ideológico básico, lo reformuló bajo nuevos y dinámicos parámetros: la nación de la fe construida en el mundo de la impiedad, no fue la formulación dogmática, rígida y anquilosada que atribuyen las historiografías oficiales a la acción conservadora en el continente. El proyecto político que sustentó García Moreno en Ecuador es quizá emblemático de la ágil y cambiante movilidad que le permitió permanecer en el poder durante tres lustros en circunstancias adversas.

Así como el monarquismo mexicano murió con la derrota del Segundo Imperio, el ecuatoriano lo hizo de manera menos vistosa pero igualmente radical. A partir de 1862, y por más dificultades y peligros que corriera Ecuador, nadie revivió la propuesta. Si bien el ejemplo de México fue sin duda aleccionador para todo el continente, quizá el monarquismo no fue en Ecuador, como en otros países de la región, mucho más que la expresión del desencanto y el cansancio de unas élites que, a medida que avanzaba el siglo, fueron madurando y visualizando otras alternativas para resolver la suerte de sus conflictivos estados. El proyecto garciano mostró una dirección posible. Ningún otro volvió a recorrer el mismo camino. El torbellino de la historia se había encargado de hacerlo intransitable. 


\section{SIGLAS Y REFERENCIAS}

LC Library of Congress, Washington, DC. Microfilms, Periódico El Nacional, Quito.

AMAE, MQO, Archivos del Ministerio de Asuntos Exteriores. Mi-

CPC nisterio del Quai d’Orsay, Correspondencia política de los cónsules, París.

Agramonte, Roberto

Biografía del dictador García Moreno: estudio psicopatológico e histórico, La Habana, Cultura, 1935.

Ayala Mora, Enrique

Lucha politica y origen de los partidos en Ecuador, Quito, Pontificia Universidad Católica del Ecuador, 1978.

“Gabriel García Moreno y la gestación del Estado nacional”, en Labastida Martín del Campo, 1986, pp. 124-160.

"El periodo garciano: panorama histórico", en Ayala Mora y Cordero, 1990, pp. 197-235.

"El origen del nombre América Latina y la tradición católica del siglo XIx", en Anuario Colombiano de Historia Social y de la Cultura, 40:1 (2013), pp. 213-241.

Ayala Mora, Enrique y Rafael Cordero (eds.)

Nueva historia del Ecuador, Quito, Corporación Editora Nacional, Grijalbo Ecuatoriana, 1990, vol. 8.

Benítez Vinuenza, Leopoldo

Ecuador: drama y paradoja, México, Fondo de Cultura Económica, 1950.

Berthe, Agustín

García Moreno: presidente de la República del Ecuador, vengador y mártir del derecho cristiano, París, Víctor Retaux, 1892. 
Buriano, Ana

"Ecuador: un régimen conservador en épocas de liberalismo rampante”, en OrTelli y Hernández (coords.), 2007, pp. 211-256.

Navegando en la borrasca: construir la nación de la fe en el mundo de la impiedad. Ecuador, 1860-1875, México, Instituto Mora, 2008.

“Ecuador 1868: la frustración de una transición”, en Secuencia, 86 (2013), pp. 77-109.

“El 'espíritu nacional' del Ecuador católico: política y religión”, en Procesos: revista ecuatoriana de historia (2014) [en prensa].

Buriano, Ana (comp.)

El "espíritu nacional" del Ecuador católico: artículos selectos de El Nacional, 1872-1875, México, Instituto Mora, México, 2011.

CÁrdenas, María Cristina

Región y Estado nacional en el Ecuador: el progresismo azuayo del siglo XIX, 1840-1895, Quito, Academia Nacional de Historia, Universidad Pablo Olavide, 2005.

CARrión, Benjamín

García Moreno: el santo del patíbulo, México, Fondo de Cultura Económica, 1959.

Connaughton, Brian

"La larga cuesta del conservadurismo mexicano: del disgusto resentido a la propuesta partidaria, 1789-1854”, en Fow LER y Morales Moreno, 1999, pp. 169-186.

Démelas, Marie-Danielle e Yves Saint-Geours

Jerusalén y Babilonia: religión y politica en el Ecuador, 17801880, Quito, Corporación Editora Nacional, 1988. 
Diario

Diario de los trabajos de la Convención Nacional reunida en la capital de la República el año de 1861, Quito, Imprenta del Gobierno, 1861.

Foucault, Michel

Seguridad, territorio y población, México, Fondo de Cultura Económica, 2006.

Fowler, William y Humberto Morales Moreno (comps.)

El conservadurismo mexicano en el siglo XIX, Puebla, Benemérita Universidad Autónoma de Puebla, Saint Andrews University, Department of Spanish School of Modern Languages, Gobierno del Estado de Puebla, 1999.

GÁlvez, Manuel

Vida de Gabriel García Moreno, Buenos Aires, Difusión, 1942.

Gimeno, Ana

Una tentativa monárquica en América: el caso ecuatoriano, Quito, Centro de Investigación y Cultura, Banco Central del Ecuador, 1988.

Hassaureck, Friedrich

Cuatro años entre los ecuatorianos, Quito, Abya Yala, 1994.

Henderson, Peter

Gabriel Garcia Moreno and Conservative State Formation in the Andes, Austin, University of Texas Press, 2008.

“La Constitución ecuatoriana de 1861: el debate", en Procesos: revista ecuatoriana de historia, 30 (2009), pp. 47-69.

Howe, George

“García Moreno's Efforts to Unite Ecuador and France”, en The Hispanic American Historical Review, 16: 2 (1936), pp. 257-262. 
IrurozQui, Marta (ed.)

La mirada esquiva: reflexiones históricas sobre la interacción del Estado y la ciudadanía en los Andes, Madrid, Consejo Superior de Investigación Científica, 2005.

Labastida Martín del Campo, Julio (comp.)

Dictaduras y dictadores, México, Siglo Veintiuno Editores, Universidad Nacional Autónoma de México, 1986.

Lara, Darío

La vitrina de un país sobre el mundo: informes de los diplomáticos franceses del siglo XIX, Quito, Abya Yala, 1997.

Loor, Wilfrido (comp.)

Cartas de García Moreno, Guayaquil, Ecuador, Vida, 2da, ed., s.f.; vol. 2, 1855-1861; vol. 3, 1862-1867, Quito, Ecuatoriana, 1966; Quito, La Prensa Católica, vol. 4, 1868-1875, 1955.

Maiguashca, Juan

"El proceso de integración nacional en el Ecuador: el rol del poder central, 1830-1895”, en Maiguashca (ed.) 1994, pp. $355-420$.

"The Electoral Reforms of 1861 in Ecuador and the Rise of a New Political Order", en Posada Carbó, 1996, pp. 87-116.

"El proyecto garciano de modernidad católica republicana en Ecuador, 1830-1875”, en IruRozQui, 2005, pp. 233-259.

Maiguashca, Juan (ed.)

Historia y región en el Ecuador, 1830-1930, Quito, Corporación Editora Nacional, Flacso, Cerlac, 1994.

Olsina, Michèle

"Relaciones diplomáticas entre Ecuador y Francia en el siglo XIX: ¿el proyecto de un protectorado francés para el Ecuador”, en Waters y Hamerly, 2007, vol. 2, pp. 39-54. 
Ortelli, Sara y Cuauhtémoc Hernández (coords.)

América en la época de Juárez: la consolidación del liberalismo: procesos políticos, sociales y económicos, 1854-1872, México, Universidad Autónoma Metropolitana, Universidad Autónoma Benito Juárez de Oaxaca, 2007.

Palti, Elías

La invención de una legitimidad: razón y retórica en el pensamiento mexicano del siglo XIX. Un estudio sobre las formas del discurso político, México, Fondo de Cultura Económica, 2005.

El tiempo de la política: el siglo XIX reconsiderado, Buenos Aires, Fondo de Cultura Económica, 2007.

PANI, Erika

"El tiro por la culata: los conservadores y el imperio de Maximiliano", en Torre, García Ugarte y Ramírez, 2005, pp. $99-122$.

Posada Carbó, Eduardo (ed.)

Elections before Democracy: the History of Elections in Europe and Latin America, Londres, University of London, 1996.

Robalino Dávila, Luis

Orígenes del Ecuador de hoy: García Moreno, Quito, Talleres Gráficos Nacionales, 1949.

Robertson, William Spence

García Moreno's Dream of a European Protectorate, Buenos Aires, Talleres S.A. Casa Jacobo Peuser, 1942.

Rojas, Rafael

"Plumas que matan: el duelo intelectual entre Gabriel García Moreno y Juan Montalvo en el XIX ecuatoriano", en Istor: revista de historia internacional, 50 (2012), pp. 7-35.

Rosanvallon, Pierre

La consagración del ciudadano: historia del sufragio universal en Francia, México, Instituto Mora, 1999. 
Torre, Renée de la, Marta Eugenia García Ugarte y Juan Manuel RAMírez (comps.)

Los rostros del conservadurismo mexicano, México, Centro de Investigaciones y Estudios Superiores en Antropología Social, 2005.

Van Aken, Mark

El rey de la noche: Juan José Flores y el Ecuador, 1824-1864, Quito, Banco Central del Ecuador, 1995.

Waters, William y Michael Hamerly (comps.)

Estudios ecuatorianos: un aporte a la discusión, Quito, Flacso, Abya Yala, 2007, vol. 2. 
